\title{
The effect of additives on the burning rate of the silicon-calcium sulfate pyrotechnic delay compositions
}

\author{
Shepherd M. Tichapondwa* ${ }^{*}$, [a] Walter W. Focke ${ }^{[a]}$, Olinto Del Fabbro ${ }^{[a]}$, George \\ Labuschagne $^{[\mathrm{b}]}$
}

[a] S.M. Tichapondwa, W.W. Focke, O. del Fabbro

Institute of Applied Materials, Department of Chemical Engineering, University of Pretoria

Lynnwood Road, Pretoria, South Africa

Fax: (+27(0)124202516)

E-mail: tichapondwa@gmail.com

[b] G. Labuschagne

Research and Technology

AEL Mining Services

PO Modderfontein, 1645, South Africa

\begin{abstract}
The effect of fuel particle size as well as the influence of inert and reactive additives on the burning rate of the $\mathrm{Si}-\mathrm{CaSO}_{4}$ composition was evaluated. The burning rate decreased with increase in fuel particle size, while the enthalpy remained constant. Addition of fuels to the base composition increased the burning rate, with an increase from $12.5 \mathrm{~mm} \mathrm{~s}^{-1}$ to $43 \mathrm{~mm} \mathrm{~s}^{-1}$ being recorded upon $10 \mathrm{wt}$. \% Al addition. Ternary mixtures of silicon, calcium sulfate and an additional oxidizer generally decreased the burning rate, with the exception of bismuth trioxide where it increased. The $\mathrm{Si}-\mathrm{CaSO}_{4}$ formulation was found to be sensitive to the presence of inert material, addition of as little as $1 \mathrm{wt}$. \% fumed silica stifled combustion in the aluminium tubes.
\end{abstract}

Keywords: Silicon, Calcium sulfate, Particle size, Additives, Pyrotechnics

\section{Introduction}

Delay detonators are used extensively in mining, quarrying and other blasting operations in order to facilitate sequential initiation of the explosive charges in a pattern of boreholes [1]. The timing of the sequential initiation events are carefully chosen in order to control the fragmentation and throw of the rock being blasted. This approach also reduces ground vibration and air blast noise [1]. Both chemical and electronic time delay detonators are used to achieve the required time delays. The simplicity, ruggedness and low cost of pyrotechnic delays make them particularly attractive for high volume mining applications.

The delay elements used in these detonators are usually made by compacting a pyrotechnic delay compositions into small-diameter tubes made from various materials [2]. The delay compositions used should ideally burn at a constant, predetermined rate with little to no gas released [3]. The time taken for the composition to burn across the length of the delay element provides reproducible time intervals between energetic events [4]. A wide range of parameters that influence the burn behaviour of a composition should be considered when designing a delay composition [2a, 5]. Parameters such as the nature of the fuel and the oxidant, the mixture stoichiometry, particle size distributions, the presence of additives and the quality of mixing are regarded as the most important [2a]. Each parameter acts by affecting one or more of the activation energy, heat of reaction or efficiency of energy feedback [5a]. In order to produce the desired pyrotechnic effects, these variables must be optimized and held constant from batch to batch so as to attain reproducible behaviour.

The influence of particle size on the reactivity of gas-solid or liquid-solid chemical reactions is well documented [6]. Similarly this effect applies for solid-solid reactions in general and pyrotechnic reactions in particular [2a]. In the case of the burning rate, the general trend is that a decrease in particle size of either the fuel or oxidizer increases the burning rate [2b,5a,7]. The particle size effect is brought about by a reduction in the effective activation energy of the system since smaller particles require less energy to be heated to the ignition temperature. Also, as the particle size decreases, the specific surface area increases and the number of contact points between the reactants also increases [8]. The homogeneity of a two component system also increases as the particle size of at least one of the components decreases [9]. The particle size effect is typically more pronounced for the fuel particles rather than the oxidizer [5a, 8b, 10]. This is because the oxidizer decomposes at a lower temperature than the fuel (if the fuel does at all). Berger [5b] reports that the particle size of a reducing 
agent does not influence the heat of reaction. However, Bernard, et al. [11] report changes reaction enthalpy with particle size.

The burning rates of a binary system can be modified by conversion to a ternary system through incorporation of additives [12]. These additives can either be inert or chemically active. They can function as processing aids, fluxing agents, heat sinks, thermal insulators, sensitizers or catalysts within the main pyrotechnic composition. The presence of additives influences anyone of activation energy, heat of reaction or efficiency of energy feedback in a given composition [5a]. In delay composition, burning propagates by re-ignition from layer to layer along the burning path and therefore the thermal diffusivity of the mixture plays a significant role in on the burning rate [13]. Addition of inert materials may alter the thermal properties of the system leading to a reduction in the rate of heat transfer through the mix thus slowing the reaction. McLain [2]a noted that addition of inert materials with low thermal conductivities such as kaolin reduces burn rate whilst thermally conductive fine $\mathrm{Cu}$ and Ag powders increase it. Inert material may also act by reducing the contact between fuel and oxidant [12a]. Fluxing agents are metals or metal compounds that melt at temperatures lower than the burning temperature of the base composition. The molten phase increases the contact points resulting in faster burn rates and fewer failures upon ignition [1,12a]. Catalysts are sometimes used in pyrotechnic compositions, these act by lowering the decomposition temperature of the oxidizer which in turn lowers the ignition temperature of the composition [1, $5 a]$. Sensitizers are often added to compositions with a high ignition temperature. These act by reacting prior to the main reaction and providing heat that then initiates the main reaction [14].

The influence of stoichiometry on the combustion behaviour of a silicon-calcium sulfate composition has been reported [15]. The present study focuses on the use of fuel with varying particle size and addition of inert or chemically active additives as a means of modifying the burning rates of $\mathrm{Si}-\mathrm{CaSO}_{4}$ pyrotechnic delay compositions.

\section{Experimental}

\subsection{Materials}

Polycrystalline silicon powders supplied by Millrox and $\beta$-anhydrite calcium sulfate supplied by Alpha Aesar were used to determine the particle size effect. They also served as the base materials for the additive experiments. Table 1 shows the $d_{10}, d_{50}$ and $d_{90}$ particle sizes and the Brunauer, Emmett and Teller (BET) surface areas. These properties were determined using a Mastersizer Hydrosizer 2000 and a Micrometrics Tristar II BET machine, respectively. X-ray diffraction (XRD) analysis was carried out on all the raw materials and confirmed them to be of high purity. However, Type 4 silicon contained ca. 13 wt.\% $\mathrm{SiO}_{2}[16]$. Since it has a smaller particle size and a higher surface area than the other silicon powders, it can be assumed that they contained less $\mathrm{SiO}_{2}$.

Carbon black (CP grade) was supplied by Alpha Aesar. $\mathrm{CuSb}_{2} \mathrm{O}_{4}$ was synthesized according to the procedure described by Focke et al. [17]. Vermiculite (supplied by Mandoval Vermiculite), attapulgite (supplied by G\&W Base Minerals), fumed silica (Aerosil 200 supplied by Degussa) and wollastonite (supplied by Omega Chemicals) were employed as inert diluents. All the other chemicals were supplied by Sigma Aldrich.

Table 1. Particle size distribution and BET surface area properties of the material used to prepare a variety of compositions

\begin{tabular}{lcccc}
\hline Reagents & $\begin{array}{c}\mathbf{d}_{10} \\
(\boldsymbol{\mu m})\end{array}$ & $\mathbf{d}_{50}(\boldsymbol{\mu m})$ & $\begin{array}{c}\mathbf{d}_{90} \\
(\boldsymbol{\mu m})\end{array}$ & $\begin{array}{c}\mathbf{B E T}\left(\mathbf{m}^{2}\right. \\
\left.\mathbf{g}^{-1}\right)\end{array}$ \\
\hline $\begin{array}{l}\text { Silicon Type } \\
2\end{array}$ & 1.97 & 15.8 & 98.65 & 4.01 \\
$\begin{array}{l}\text { Silicon Type } \\
3\end{array}$ & 0.83 & 5.02 & 65.43 & 10.46 \\
$\begin{array}{l}\text { Silicon Type } \\
4\end{array}$ & 0.91 & 1.85 & 4.58 & 11.02 \\
CaSO $_{4}$ & 0.61 & 4.05 & 25.30 & 3.78 \\
\hline
\end{tabular}

\subsection{Composition preparation and delay element preparation}

Compositions of silicon and calcium sulfate were prepared in the fuel range of 30 to $70 \mathrm{wt} . \%$ using three different silicon powders of varying particle size. Additional $\mathrm{Si}-\mathrm{CaSO}_{4}$ compositions were prepared by addition of additives. Tables 2, 3 and 4 show the list of additive material used in the initial part of the investigation. Here 5 wt. \% of additive was either substituted or added to a base composition of $30 \mathrm{wt}$ \% Si. Type 4 silicon was used in these compositions. Based on the results obtained from the initial $5 \mathrm{wt} \%$ additive tests, selected additives were used to prepare compositions containing 1, 2, 5, 7.5 and 10 wt.\% additive concentrations. Another set of compositions was also prepared in which 5 wt.\% of $\mathrm{Si}$ was substituted with an equivalent amount of aluminium for compositions 
in the fuel range of 30 to $70 \mathrm{wt} . \%$. All these powders were mixed by brushing them several times through a $75 \mu \mathrm{m}$ sieve.

The compositions were pressed into $25 \mathrm{~mm}$ long aluminium tubes with an internal diameter of $3.6 \mathrm{~mm}$ and a wall thickness of $1.45 \mathrm{~mm}$. The filling process started with two increments of a proprietary starter composition pressed with a $100 \mathrm{~kg}$ load. This was followed by repeated steps of adding two increments of the delay composition and pressing it with the same load until the tube was filled.

\subsection{Burning rate measurements}

The burning rates were determined using commercial detonator assemblies. The detonators comprised an initiating shock tube coupled to a rigid aluminium time delay element contained in an aluminium shell. This outer shell contained increments of lead azide primary explosive and pentaerythritol tetranitrate (PETN) as the secondary explosive. The actual delay time was determined using the method described by llunga, et al. [14] and Tichapondwa, et al. [15].

\subsection{Characterization}

Thermogravimetric analysis (TGA) was performed on a Mettler Toledo A851 TGA/SDTA using the dynamic method. About $15 \mathrm{mg}$ of powder sample was placed in an open $70 \mu \mathrm{L}$ alumina pans. Temperature was scanned from 25 to $1200{ }^{\circ} \mathrm{C}$ at a rate of $10^{\circ} \mathrm{C} \mathrm{min}{ }^{-1}$ with oxygen flowing at a rate of $50 \mathrm{~mL} \mathrm{~min}^{-1}$. Three runs were carried out for each sample.

Enthalpy measurements were carried out using a Parr 6200 calorimeter utilizing a 1104B $240 \mathrm{~mL}$ high strength bomb. Tap compacted test compositions $(2 \mathrm{~g})$ were initiated using $0.2 \mathrm{~g}$ of a proprietary starter. It was ignited with an electrically heated 30 gauge nichrome wire. The tests were carried out in a $3.0 \mathrm{MPa}$ helium atmosphere. The variation of pressure with time was followed using a National Instruments piezoelectric transducer. A Parr Dynamic Pressure Recording System was used for data collection. The recording frequency was $5 \mathrm{kHz}$ and 30000 data points were captured per test. Each composition was tested at least three times.

\section{Results}

\subsection{Effect of particle size}

\subsubsection{Thermal stability of reactants}

Figure 1 shows the oxidation behavior of silicon powders with different particle sizes. Type 3 and 4 silicon had similar thermal behavior throughout the temperature range tested and attained similar mass gains. However, Type 2 silicon which had larger particles with lower surface area showed a lower mass increase. The theoretical mass increase, assuming total conversion, was expected to be approximately $114 \%$, however this was not attained. Silicon dioxide acts as a passivation layer for the underlying silicon impeding the diffusion of oxygen to the reaction interface [16]. The thermal stability of calcium sulfate is also shown in Figure 1. The anhydrous $\mathrm{CaSO}_{4}$ was stable beyond $1000^{\circ} \mathrm{C}$ with the onset of decomposition above $1100^{\circ} \mathrm{C}$. 


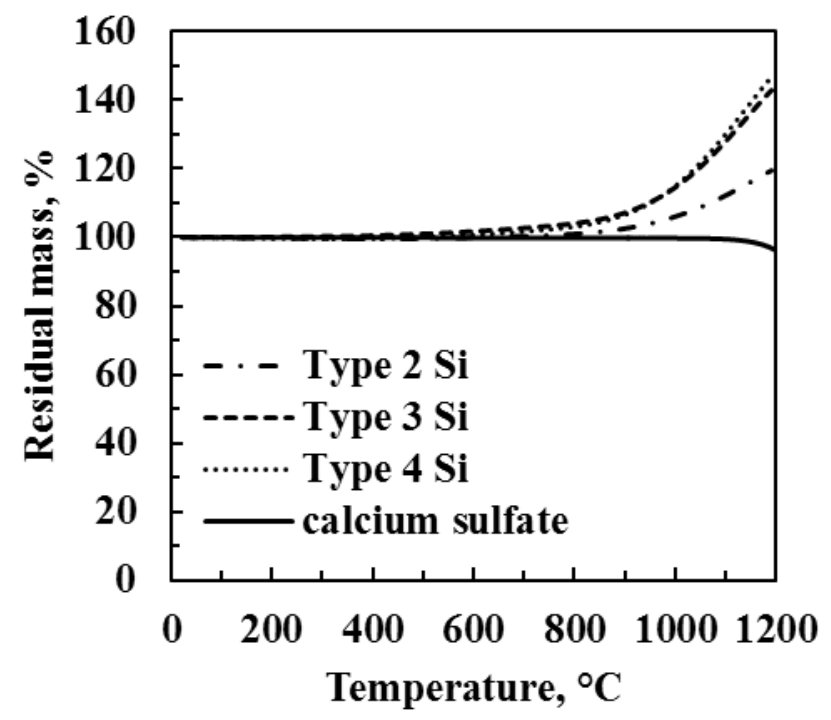

Figure 1. TGA results for silicon powders with different particle size and calcium sulfate in an oxygen atmosphere.

\subsubsection{Effect of particle size on the energy output}

The effect of the silicon stoichiometry and particle size on the energy output of $\mathrm{Si}-\mathrm{CaSO}_{4}$ compositions is shown in Figure 2. The general trend was that energy output decreased linearly with increase in Si content. The energy outputs for compositions with the same fuel content but different particle size was almost similar. These results were analogous to observations by Berger, et al. [10] who reported that the particle size of the reducing agent does not influence the heat of reaction. However, other researchers have recorded slight increases in the heat of reaction for compositions with smaller particle sizes [5a, 11]. These observations can be attributed to the smaller particles having a higher probability of attaining complete combustion.

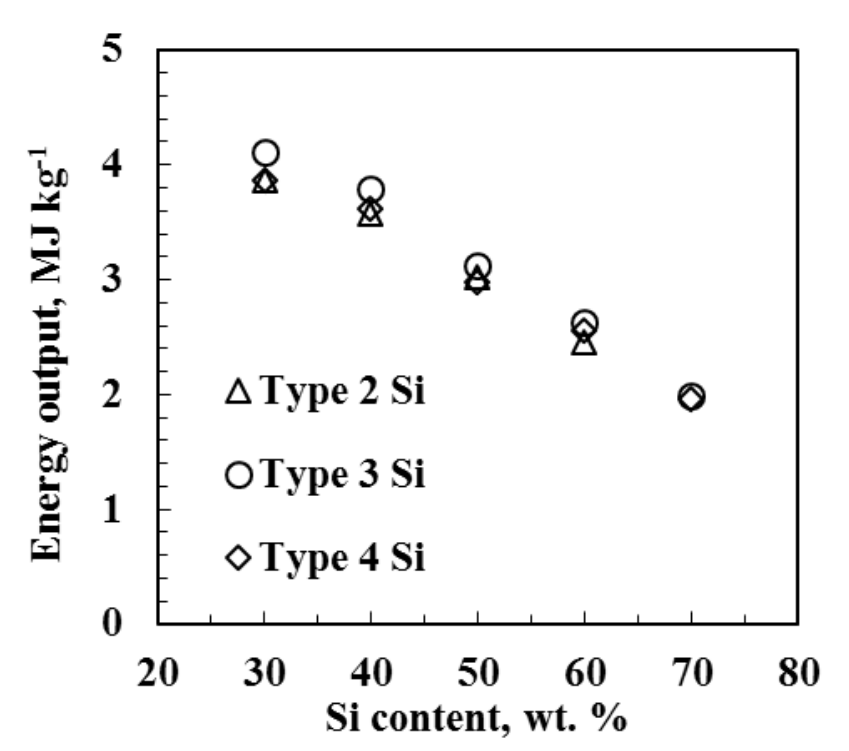

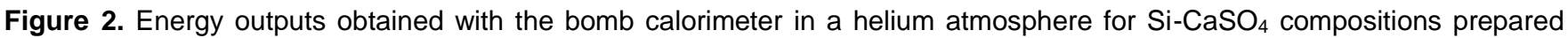
using silicon powders with different particle sizes.

\subsubsection{Effect of particle size on the pressure response time}

The time-dependent changes in pressure, relative to the initially applied helium pressure of $3.0 \mathrm{MPa}$, for the 30 wt. $\% \mathrm{Si}-\mathrm{CaSO}_{4}$ compositions prepared using silicon of varying particle size are shown in Figure 3. Table 2 shows the parameters extracted from these profiles. There was a clear trend with the rate of pressure rise, as well as the maximum peak pressure, increasing with decreasing particle size. The time to reach maximum pressure 
increased with increase in particle size, with the Type 2 silicon taking 1.26 seconds whilst the Type 4 silicon took 1.14 seconds. The increase in pressure for this system resulted primarily from a rise in temperature within the closed bomb system rather than from the amount of evolved gas [15]. Since the energy released by the three different particle sizes was almost comparable, the marked difference in the pressure profiles was attributed to a variation in the rate of heat release.

Table 2. Energy output, peak pressures, times to reach the peak pressure and the maximum pressurization rates extracted

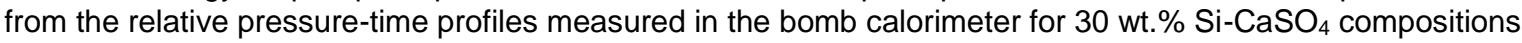

\begin{tabular}{|c|c|c|c|}
\hline Silicon used & Type 2 & Type 3 & Type 4 \\
\hline$\overline{P_{\max }(\mathrm{MPa})}$ & 1.72 & 2.06 & 2.38 \\
\hline$t_{\max }(\mathrm{s})$ & 1.26 & 1.20 & 1.14 \\
\hline$d P / d t_{\max }\left(\mathrm{MPa} \mathrm{s}^{-1}\right)$ & 3.04 & 4.45 & 4.62 \\
\hline Energy output $\left(\mathrm{MJ} \mathrm{kg}^{-1}\right)$ & 3.87 & 3.87 & 3.87 \\
\hline
\end{tabular}

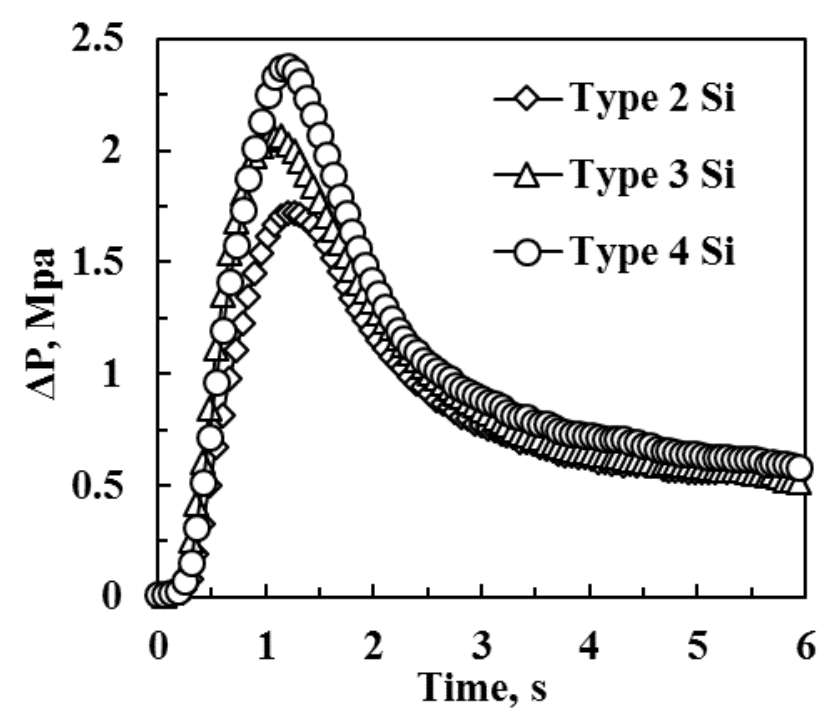

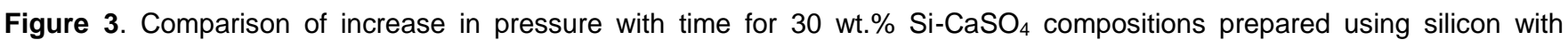
different particle sizes tested during the bomb calorimetry experiments in a helium atmosphere.

\subsubsection{Effect of particle size on burning rates}

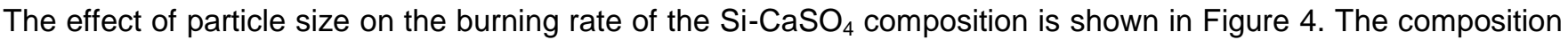
prepared using smallest particle size, Type 4 silicon $\left(d_{50}=1.85 \mu \mathrm{m}\right)$, had the fastest burning rates $\left(6.9-12.5 \mathrm{mms}^{-}\right.$ $\left.{ }^{1}\right)$. Compositions prepared from Type 3 silicon $\left(d_{50}=5.02 \mu \mathrm{m}\right)$ had slightly lower burning rates which ranged from 6.6 to $11.0 \mathrm{mms}^{-1}$. However, compositions based on the coarser silicon Type 2 grade showed a decrease in burn rate by nearly a factor of two. Also, unlike the compositions prepared from the other two silicon samples which sustained burning in the range of 30 to $70 \mathrm{wt}$. \% silicon, the Type 2 compositions only sustained burning for the 30 and $40 \mathrm{wt}$. \% silicon, respectively. The decrease in burning rate was attributed to a decrease in the active surface area and number of contact points within the particles of a given composition [8]. The larger particles also required more energy over a longer time period to heat them up to the required reaction temperature compared to the smaller particles, which increases the activation energy and results in lower burn speeds [5a]. 


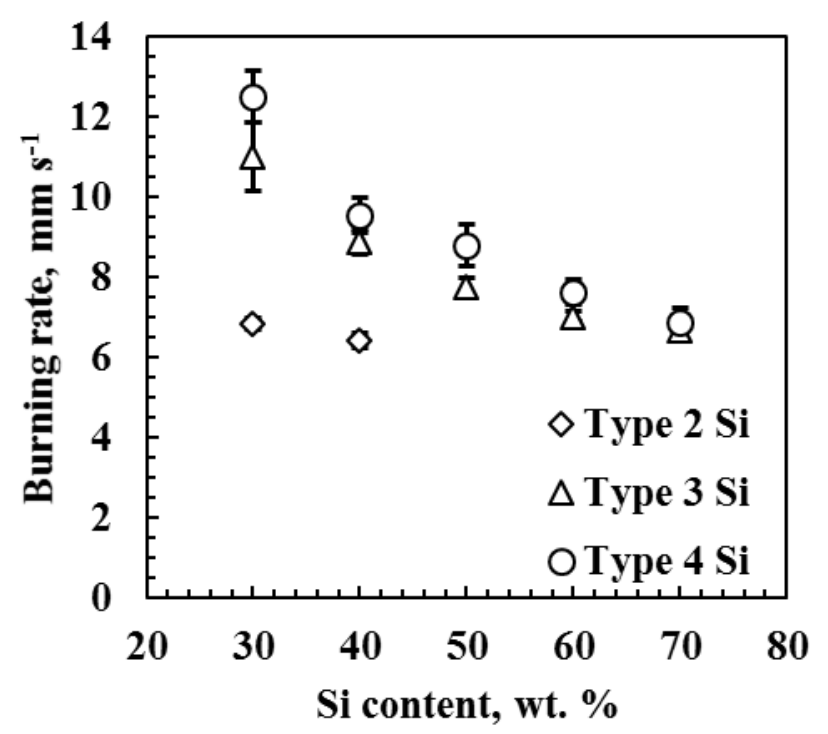

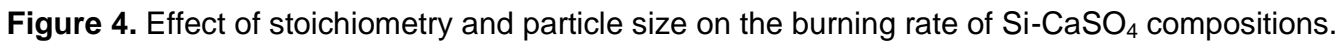

Table 3. The effect of additive fuel on the burning rate and energy output of a 30 wt. $\% \mathrm{Si}-\mathrm{CaSO}_{4}$ composition $(25 \% \mathrm{Si}+5 \%$ fuel additive $\left.+70 \% \mathrm{CaSO}_{4}\right)$. The median particle size $\left(\mathrm{d}_{50}\right)$ and BET surface area properties of the fuels used is also indicated.

\begin{tabular}{lcccc}
\hline Fuel & $\begin{array}{c}\text { Particle } \\
\text { size } \mathbf{d}_{50,} \\
(\boldsymbol{\mu m})\end{array}$ & $\begin{array}{c}\text { BET } \\
\text { surface } \\
\text { area, }\left(\mathbf{m}^{2}\right. \\
\left.\mathbf{g}^{-1}\right)\end{array}$ & $\begin{array}{c}\text { Energy } \\
\text { output, } \\
\left(\mathbf{M J ~ k g}^{-}\right. \\
\mathbf{1})\end{array}$ & $\begin{array}{c}\text { Burning } \\
\text { rate, } \\
\left(\mathbf{m m ~ s}^{-1}\right)\end{array}$ \\
\hline Control & - & - & $3.8 \pm 0.04$ & $12.7 \pm 0.7$ \\
B & 2.1 & 6.7 & $3.9 \pm 0.03$ & $16.6 \pm 1.7$ \\
Mn & 23.4 & 0.3 & $4.1 \pm 0.03$ & $18.9 \pm 1.3$ \\
Al & 10.2 & 0.1 & $4.3 \pm 0.13$ & $31.8 \pm 3.2$ \\
W & 6.3 & 0.2 & $3.9 \pm 0.08$ & $\#$ \\
S & - & 4.2 & $4.1 \pm 0.08$ & $\#$ \\
C & 10.8 & 75.0 & $3.4 \pm 0.08$ & $\#$ \\
\hline
\end{tabular}

${ }^{\#}$ Did not sustain burning in the aluminium tubes

\subsection{Influence of additives on the $\mathrm{Si}-\mathrm{CaSO}_{4}$ pyrotechnic reaction}

\subsubsection{Effect of fuel substitution on burn rate}

The effect of substituting 5 wt. \% of silicon with an alternative fuel on the burning rate and energy output of a 30 wt. \% Si-CaSO ${ }_{4}$ composition is shown in Table 3. All the compositions prepared ignited during bomb calorimetry in an inert helium atmosphere. The energy outputs for all the compositions $\left(4.04 \pm 0.16 \mathrm{MJ} \mathrm{kg}^{-1}\right)$ were slightly higher than the energy recorded for the binary control composition $\left(3.87 \pm 0.04 \mathrm{MJ} \mathrm{kg}^{-1}\right)$. The carbon black substituted composition however had a significantly lower energy output of $3.40 \pm 0.01 \mathrm{MJ} \mathrm{kg}^{-1}$. Substitution of silicon with alternative fuels increased the burning rate, with the highest burning rate recorded for the aluminium substituted composition $\left(31.8 \mathrm{~mm} \mathrm{~s}^{-1}\right)$. However, the formulations prepared using tungsten, sulfur and carbon did not propagate in the aluminium tubes. Carbon and calcium sulfate are known to undergo endothermic redox reactions at high temperatures [18]. It is was postulated that addition of small amounts carbon would reduce the burning rate by reducing the fraction of energy fed forward to the adjacent unreacted layers in the packed tubes. Although tungsten has a higher thermal conductivity compared to silicon, it has a lower thermal diffusivity [13a]. The tungsten therefore is less effective at transmitting the thermal energy, stifling propagation along the length of the tubes. Sulfur has a low melting temperature $\left(115^{\circ} \mathrm{C}\right)$ and was expected to act as a flux upon melting and possibly increase the burning rate. However, sulfur also has a low vaporization temperature $\left(445^{\circ} \mathrm{C}\right)$ which is lower than the ignition temperature of the composition hence the fluxing effect is lost as sulfur turns to gas and takes away energy from the system during the vaporization [19].The fast burning rates obtained with aluminium 
were attributed to a combined effect of the aluminium acting as a flux as it melts at $660{ }^{\circ} \mathrm{C}$, and increasing the overall thermal diffusivity of the mixture.

\subsubsection{Effect of fuel substitution on burn rate}

Table 4 reports the effect of replacing 5 wt.\% of $\mathrm{CaSO}_{4}$ with an alternative oxidizer. The substitution did not have an appreciable effect on the energy output of the reaction, however, effects of the burn rate were noted. Substitution with $\mathrm{V}_{2} \mathrm{O}_{5}, \mathrm{Sb}_{2} \mathrm{O}_{3}$ and $\mathrm{CuSb}_{2} \mathrm{O}_{4}$ decreased the burning rate from $12.5 \mathrm{~mm} \mathrm{~s}^{-1}$ to $10.6,10.9$ and 11.4 $\mathrm{mm} \mathrm{s}^{-1}$, respectively. A faster burning rate of c.a. $16.8 \mathrm{~mm} \mathrm{~s}^{-1}$ was recorded upon substitution with bismuth trioxide $\left(\mathrm{Bi}_{2} \mathrm{O}_{3}\right)$. Compositions substituted with $\mathrm{MnO}_{2}$ and $\mathrm{CuO}$ did not sustain combustion when pressed into aluminium tubes. Several metal oxides such as $\mathrm{SiO}_{2}, \mathrm{Fe}_{2} \mathrm{O}_{3}, \mathrm{Al}_{2} \mathrm{O}_{3}$ and $\mathrm{ZnO}$ reportedly have catalytic properties reducing the calcium sulfate decomposition onset temperature by as much as $200{ }^{\circ} \mathrm{C}$ [20]. However, in the present study all the oxidizers except $\mathrm{Bi}_{2} \mathrm{O}_{3}$ either reduced the burning rate or stopped propagation altogether. This suggests that catalytic activities were not operative. The $\mathrm{Si}_{-} \mathrm{Bi}_{2} \mathrm{O}_{3}$ reaction is a known low activation energy, fast burning reaction, therefore the increase noted in the $\mathrm{Si}-\mathrm{CaSO}_{4}-\mathrm{Bi}_{2} \mathrm{O}_{3}$ composition was attributed more to the additive acting as a sensitizer rather than as a catalyst [14]. Beck and Flanagan [1] patented the use of $\mathrm{V}_{2} \mathrm{O}_{5}$ which has a melting temperature of $600^{\circ} \mathrm{C}$ as a fluxing agent in the $\mathrm{Si}^{-B S_{3}}{ }_{4}$ reaction. Their results showed comparable burning rates regardless of the addition of $\mathrm{V}_{2} \mathrm{O}_{5}$. In addition $\mathrm{V}_{2} \mathrm{O}_{5}$-containing compositions feature fewer failures. In the present results, addition of $\mathrm{V}_{2} \mathrm{O}_{5}$ slightly increased the energy output but lowered the burning rate of the reaction. This implies that $\mathrm{V}_{2} \mathrm{O}_{5}$ did not participate in the reaction or alter its pathway. The lower burn rates are possibly due to some of the energy being used up in melting the $\mathrm{V}_{2} \mathrm{O}_{5}$ resulting in a lower fraction of energy being fed forward to the next layers.

\subsubsection{Effect of addition of diluents on burn rate}

Inert materials are deliberately added to a composition so as to slow down the burning rate to a desirable speed $[2 \mathrm{a}, 12 \mathrm{a}, 19]$. Ideally these inert materials are not expected to participate in the pyrotechnic reaction. Rather they function as thermal insulators that retard the rate of layer by layer propagation within the composition. A fixed 5 wt. \% of several inert materials was added to the $30 \mathrm{wt}$. \% Si-CaSO ${ }_{4}$ composition. All the compositions ignited in the bomb calorimeter and featured heats of reaction that were comparable to the control (Table 5). However, none of these compositions sustained burning when pressed into the aluminium elements. This also includes the composition which had fumed silica added, it has been previously shown to either increase or maintain the burning rate in several compositions as it acts as a mixing aid [2b, $7 a, 21]$. It was postulated that besides the thermal insulation effect of the inert materials, their addition also increases the activation energy of the composition making it more difficult to ignite. The collective effect of these variables can be summarized using the Frank-Kamenetzky diagram which defines the conditions necessary for a reaction to ignite and propagate [22].

Table 4. Effect of oxidizer additives on the burning rate and energy output of a 30 wt.\% $\mathrm{Si}-\mathrm{CaSO}_{4}$ composition $(30 \% \mathrm{Si}+65 \%$ $\mathrm{CaSO}_{4}+5 \%$ oxidizer). The median particle size $\left(\mathrm{d}_{50}\right)$ and BET surface area properties of these oxidizers is also shown.

\begin{tabular}{|c|c|c|c|c|}
\hline Oxidizer & $\begin{array}{l}\text { Particle } \\
\text { size } \\
d_{50} \\
(\mu \mathrm{m})\end{array}$ & $\begin{array}{l}\text { BET } \\
\text { surface } \\
\text { area, }\left(\mathrm{m}^{2} \mathrm{~g}^{-}\right. \\
\left.{ }^{1}\right)\end{array}$ & $\begin{array}{l}\text { Energy } \\
\text { output, } \\
\text { (MJ kg- } \\
\text { 1) }\end{array}$ & $\begin{array}{l}\text { Burning } \\
\text { rate, }\left(\mathrm{mm} \mathrm{s}^{-}\right. \\
\left.{ }^{1}\right)\end{array}$ \\
\hline Control & - & - & $3.8 \pm 0.04$ & $12.7 \pm 0.7$ \\
\hline $\mathrm{V}_{2} \mathrm{O}_{5}$ & 10.1 & 5.5 & $4.0 \pm 0.02$ & $10.6 \pm 1.5$ \\
\hline $\mathrm{Sb}_{2} \mathrm{O}_{3}$ & 0.9 & 2.4 & $3.8 \pm 0.04$ & $10.9 \pm 1.5$ \\
\hline $\mathrm{CuSb}_{2} \mathrm{O}_{4}$ & 9.3 & 1.1 & $3.9 \pm 0.06$ & $11.4 \pm 1.3$ \\
\hline $\mathrm{Bi}_{2} \mathrm{O}_{3}$ & 8.8 & 0.8 & $4.0 \pm 0.06$ & $16.8 \pm 0.9$ \\
\hline $\mathrm{MnO}_{2}$ & 8.3 & 13.6 & $4.2 \pm 0.05$ & \# \\
\hline $\mathrm{CuO}$ & 12.7 & 1.6 & $3.9 \pm 0.07$ & \# \\
\hline
\end{tabular}

\# Did not sustain burning in the aluminium tubes 
Table 5. Effect of addition of $5 \mathrm{wt}$. \% inert materials on the energy output and burning rate of a $30 \mathrm{wt}$ \% $\mathrm{Si}_{-\mathrm{CaSO}} \mathrm{Composition}$ $\left(30 \% \mathrm{Si}+70 \% \mathrm{CaSO}_{4}+5 \%\right.$ inert material). The median particle size $\left(\mathrm{d}_{50}\right)$ and BET surface area properties of these additives is also shown.

\begin{tabular}{|c|c|c|c|}
\hline Fuel & $\begin{array}{l}\text { Particle } \\
\text { size } \\
d_{50} \\
(\mu \mathrm{m})\end{array}$ & $\begin{array}{l}\text { BET } \\
\text { surface } \\
\text { area, }\left(\mathrm{m}^{2} \mathrm{~g}^{-}\right. \\
\left.{ }^{1}\right)\end{array}$ & $\begin{array}{l}\text { Energy } \\
\text { output, (MJ } \\
\mathbf{k g}^{-1} \text { ) }\end{array}$ \\
\hline Control & - & - & $3.8 \pm 0.04$ \\
\hline Fumed Silica & - & - & $3.7 \pm 0.11$ \\
\hline Vermiculite & 10.7 & 15.8 & $3.8 \pm 0.81$ \\
\hline Silica & 9.7 & 1.3 & $3.9 \pm 0.10$ \\
\hline Wollastonite & 115 & 0.1 & $4.0 \pm 0.05$ \\
\hline Attapulgite & 9.7 & 72.9 & $4.0 \pm 0.05$ \\
\hline
\end{tabular}

\subsubsection{Effect of additive content on the burn rate of the stoichiometric composition for selected additives}

Based on the results reported in Tables 3, 4 and 5, Al, $\mathrm{V}_{2} \mathrm{O}_{5}, \mathrm{Bi}_{2} \mathrm{O}_{3}$ and fumed silica were chosen for further investigation. The fumed silica was included in this set of additives to ascertain that its effect on the composition was not a result of too much inert material having been added in the compositions reported in Table 5. In these tests, the amount of additive added or substituted to the $\mathrm{Si}-\mathrm{CaSO}_{4}$ base composition ranged from 1 to $10 \mathrm{wt} \%$. Figure 5 reports the burning rates obtained. In the case of aluminium the burning rate increased with increase in the amount added with the $10 \mathrm{wt} . \%$ composition having a burning rate of $43 \mathrm{~mm} \mathrm{~s}^{-1}$ i.e. $244 \%$ increase in burning rate. Substitution of $\mathrm{CaSO}_{4}$ with of $\mathrm{Bi}_{2} \mathrm{O}_{3}$ also resulted in an increase in burning rate with increase in the amount of $\mathrm{Bi}_{2} \mathrm{O}_{3}$ substituted. This increase occurred until the $5 \mathrm{wt} . \%$ composition, thereafter the burning rate remained constant at c.a. $17.4 \mathrm{~mm} \mathrm{~s}^{-1}$. Vanadium pentoxide resulted in a decrease in burning rate with increase in amount added i.e. from 12.5 to $8.7 \mathrm{~mm} \mathrm{~s}^{-1}$, increasing the amount from 7.5 to $10 \mathrm{wt} \%$ did not result in any further decrease. Addition of $1 \mathrm{wt} . \%$ of fumed silica stifled combustion in the aluminium tubes. This indicates that the Si$\mathrm{CaSO}_{4}$ composition is very sensitive to presence of inert diluents.

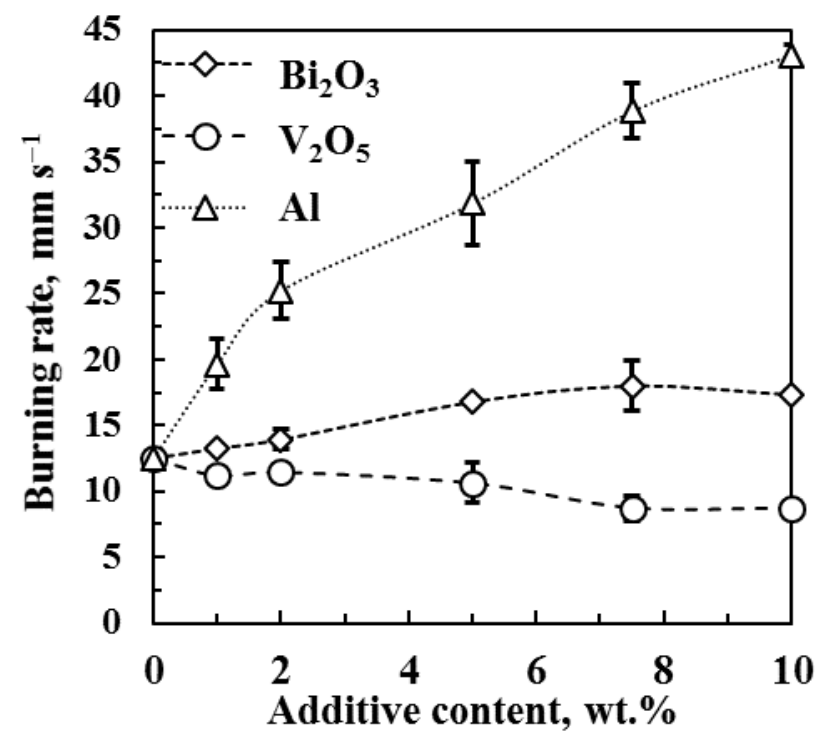

Figure 5. Effect of the amount of additive substituted on the burning rate of the 30 wt. \% $\mathrm{Si}-\mathrm{CaSO}_{4}$ composition

\subsubsection{Effect of 5 wt. \% Al substitution of Si in the $30-70$ wt. \% fuel range}

Figure 6 shows the burn rates obtained when 5 wt. \% of the silicon fuel was substituted with an equal mass of aluminium powder in the 30 to $70 \mathrm{wt}$ \% fuel range. The influence of the aluminium addition was more pronounced in the 30 and 40 wt. \% fuel compositions. The burning rate for these two composition increased from $12.5 \mathrm{~mm} \mathrm{~s}^{-1}$ to $36.7 \mathrm{~mm} \mathrm{~s}^{-1}$ and $9.5 \mathrm{~mm} \mathrm{~s}^{-1}$ to $23.9 \mathrm{~mm} \mathrm{~s}^{-1}$, respectively. The compositions with a fuel composition of 50 wt.\% and above had comparable burn rates regardless of the Al addition. The influence of Si substitution with aluminium at different fuel stoichiometries on the energy output of the composition is shown in Figure 7. The energy outputs increased by approximately $0.31 \mathrm{MJ} \mathrm{kg}^{-1}$, for the all the fuel stoichiometries tested. This indicates 
that the aluminium participated in the reaction which in turn altered the reaction mechanism. EKVI simulations of these compositions further collaborate this assertion as they revealed product spectra that were different compared to that predicted for the base composition [15]. The markedly lower burning rates recorded for compositions at $50 \mathrm{wt}$.\% fuel and beyond were thought to result from absorption of energy by the excess fuel, thus taking heat from the main reaction.

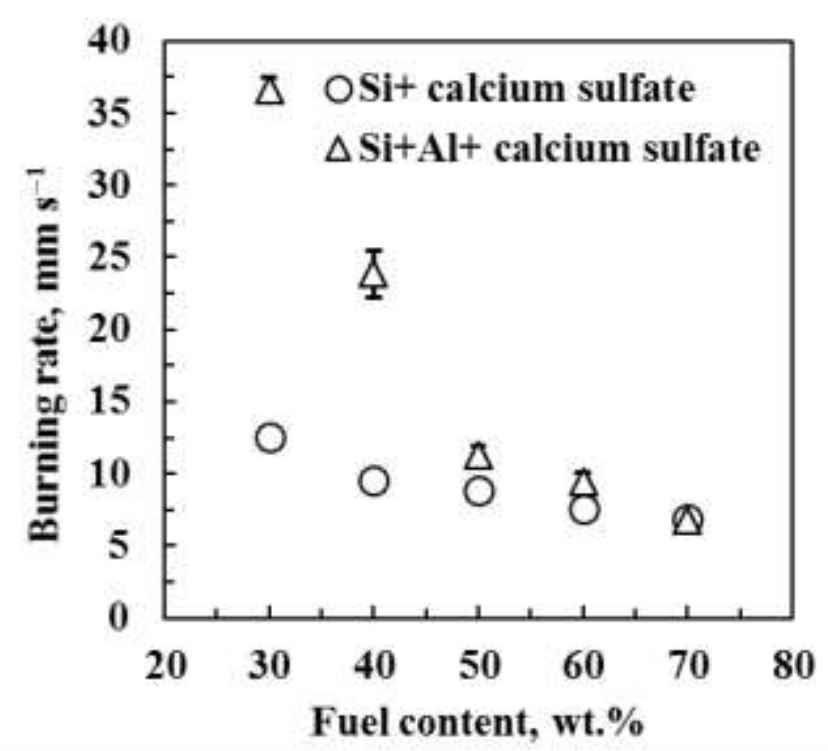

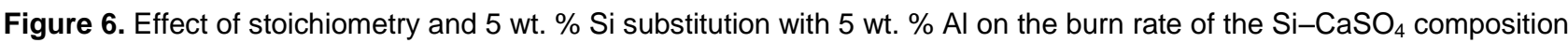

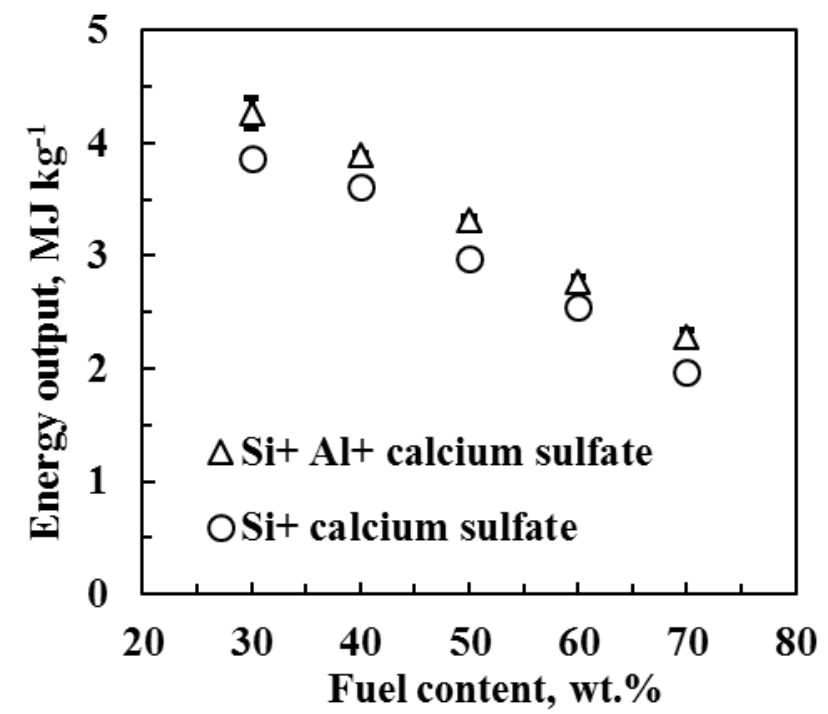

Figure 7. Effect of stoichiometry and $5 \mathrm{wt}$. \% Si substitution with aluminium on the energy output of the $\mathrm{Si}-\mathrm{CaSO}_{4}$ composition

\section{Conclusion}

The influence of fuel particle size and the addition of various additives on the burning properties of the $\mathrm{Si}-\mathrm{CaSO}_{4}$ reaction was investigated. Differences in fuel particle size had no effect on the energy outputs of the reaction. However, the burning rates decreased with increasing particle size. It was also shown that the burning rate of the $\mathrm{Si}-\mathrm{CaSO}_{4}$ composition can be tuned to burn faster or slower using a wide range of additives. Fuel based additives generally increased the combustion velocity whilst oxidizers reduced it. An exception was noted for bismuth trioxide where the burn rate increased. The base composition was established to be sensitive to the presence of unreactive diluents even at low concentrations as formulations tested did not ignite or propagate when pressed into aluminium tubes. 


\section{Acknowledgements}

This work is based on the research supported in part by AEL Mining Service and by the National Research Foundation of South Africa (Grant 83874). The opinions, findings and conclusions or recommendations expressed in this publication are those of the authors, and neither AEL Mining Services nor the NRF accept any liability whatsoever in this regard.

\section{References}

[1] M. W. Beck, J. Flanagan, Delay Composition and Device, US Patent 5, 147, 476, Imperial Chemical Industries PLC, London, England 1992.

[2] [2a] J. H. McLain, Pyrotechnics: From the Viewpoint of Solid State Chemistry, The Franklin Institute Press, Philadelphia, 1980; [2b] L. Kalombo, O. Del Fabbro, C. Conradie, W. W. Focke, $\mathrm{Sb}_{6} \mathrm{O}_{13}$ and $\mathrm{Bi}_{2} \mathrm{O}_{3}$ as Oxidants for Si in Pyrotechnic Time-delay Compositions, Propellants Explos. Pyrotech. 2007, 32, 454; [2c] E. J. Miklaszewski, J. C. Poret, A. P. Shaw, S. F. Son, L. J. Groven,Ti/C-3Ni/Al as a Replacement Time Delay Composition, Propellants Explos. Pyrotech. 2014, 39, 138.

[3] E. Charsley, C.-H. Chen, T. Boddington, P. Laye, J. Pude, Differential Thermal Analysis and Temperature Profile Analysis of Pyrotechnic Delay Systems: Ternary Mixtures of Silicon, Boron and Potassium dichromate, Thermochimica Acta 1980, 35, 141.

[4] [J. C. Poret, A. P. Shaw, C. M. Csernica, K. D. Oyler, D. P. Estes, Development and Performance of the $\mathrm{W} / \mathrm{Sb}_{2} \mathrm{O}_{3} / \mathrm{KIO}_{4} /$ Lubricant Pyrotechnic Delay in the US Army Hand-Held Signal, Propellants Explos. Pyrotech. 2013, 38, 35.

[5] [5a] K. Kosanke, B. Kosanke, B. Sturman, T. Shimizu, M. Wilson, I. Von Maltitz, R. Hancox, N. Kubota, C. Jennings-White, D. Chapman, Pyrotechnic Chemistry, Pyrotechnic Reference Series, No. 4, Journal of Pyrotechnics Inc. \& CarnDu Ltd, Huntingdon, UK, 2004; [5b] B. Berger, Parameters Influencing the Pyrotechnic Reaction, Propellants Explos. Pyrotech. 2005, 30, 27; [5c] S. Yoganarasimhan, O. Josyulu, Reactivity of The Ternary Pyrotechnic System Red Lead-Silicon-Ferric Oxide, Defence Sci. J. 2014, 37, 73.

[6] [6a] D. G. Peacock, J. F. Richardson, Chemical Engineering. Volume 3: Chemical and Biochemical Reactors \& Process Control, Elsevier Science \& Technology, 2012; [6b] O. Levenspiel, Chemical Reaction Engineering, Ind. Eng. Chem. Res. 1999, 38, 4140.

[7] [7a] R. A. Rugunanan, Intersolid Pyrotechnic Reactions of Silicon, PhD Thesis, Rhodes University, Grahamstown, South Africa 1991; [7b] I. Ricco, W. Focke, C. Conradie, Alternative Oxidants for Silicon Fuel in Time-delay Compositions, Combust. Sci.Technol. 2004, 176, 1565.

[8] [8a] A. Shimizu, J. Saitou, Y.-J. Hao, Effect of Contact Points between Particles on the Reaction Rate in the $\mathrm{Fe}_{2} \mathrm{O}_{3} . \mathrm{V}_{2} \mathrm{O}_{5}$ System, Solid State lonics 1990, 38, 261; [8b] M. E. Brown, S. J. Taylor, M. J. Tribelhorn, FuelOxidant Particle Contact in Binary Pyrotechnic Reactions, Propellants Explos. Pyrotech. 1998, 23, 320; [8c] S. Valliappan, J. A. Puszynski, Combustion Characteristics of Metal-based Nanoenergetic Systems, Proc. S. Dakota Acad. of Sci. 2003, 82, 97.

[9] S.-T. Oh, T. Sekino, K. Niihara, Effect of Particle Size Distribution and Mixing Homogeneity on Microstructure and Strength of Alumina/Copper Composites, Nanostruct. Mater. 1998, 10, 327.

[10] B. Berger, B. Haas, G. Reinhard, Influence of the Particle Size of the Reducing Agent on the Reaction Parameters of Pyrotechnic Redox Systems, 27th International Annual Conference of the Fraunhofer ICT, Fraunhofer-Institut für Chemische Technologie Jahrestagung, Karlsruhe, Germany, 25-28 June, 1996.

[11] M. L. Bernard, A. Espagnaq, R. Branka, On the Importance of Thermochemical Parameters in Solid-Solid Pyrotechnic Reactions, 7th International Pyrotechnics Seminar, Vail, Colorado, USA, 14-18 July, 1980.

[12] [12a] M. W. Beck, M. E. Brown, Modification of the Burning Rate of Antimony/Potassium Permanganate Pyrotechnic Delay Compositions, Combust. Flame 1986, 66, 67; [12b] R. A. Rugunanan, M. E. Brown, Combustion of Binary and Ternary Silicon/Oxidant Pyrotechnic Systems, Part I: Binary Systems with $\mathrm{Fe}_{2} \mathrm{O}_{3}$ and $\mathrm{SnO}_{2}$ as Oxidants, Combust. Sci.Technol. 1993, 95, 61.

[13] [13a] B. Khaikin, A. Merzhanov, Theory of Thermal Propagation of a Chemical Reaction Front, Combust. Explo. Shock+. 1966, 2, 22; [13b] R. Hill, L. Sutton, R. Temple, A. White, Slow Self-Propagating Reactions in Solids, Research 1950, 3, 569. 
[14] K. Ilunga, O. Del Fabbro, L. Yapi, W. W. Focke, The Effect of $\mathrm{Si}_{-} \mathrm{Bi}_{2} \mathrm{O}_{3}$ on the Ignition of the Al-CuO Thermite, Powder Technol. 2011, 205, 97.

[15] S. M. Tichapondwa, W. W. Focke, O. Del Fabbro, C. Kelly, Calcium Sulfate as a Possible Oxidant in "Green" Silicon-based Pyrotechnic Time Delay Compositions, Propellants Explos. Pyrotech.2015 40, 518-525.

[16] [16a] S. M. Tichapondwa, W. W. Focke, O. Del Fabbro, E. Muller, Suppressing Hydrogen Evolution by Aqueous Silicon Powder Dispersions by Controlled Silicon Surface Oxidation, Propellants Explos. Pyrotech. 2013, 38, 48. [16b] G. Dingemans, M. Van de Sanden, W. Kessels, Excellent Si Surface Passivation by Low Temperature $\mathrm{SiO}_{2}$ using an ultrathin $\mathrm{Al}_{2} \mathrm{O}_{3}$ Capping Film, Phys. Status Solidi Rapid Res. Lett. 2011, 5, 22.

[17] W. W. Focke, S. S. Mkhize, R. Storey, O. D. Fabbro, E. Muller,Facile Synthesis of Copper Antimonite, Chem. Eng. Commun. 2014, 201, 153.

[18][18a] E. Van der Merwe, C. Strydom, J. Potgieter,Thermogravimetric Analysis of the Reaction Between Carbon and $\mathrm{CaSO}_{4} \cdot 2 \mathrm{H}_{2} \mathrm{O}$, Gypsum and Phosphogypsum in an Inert Atmosphere, Thermochim. Acta, 1999, 340, 431; [18b] J. Mu, G. Zaremba, Effect of Carbon and Silica on the Reduction of Calcium Sulfate, Thermochim. Acta, 1987, 114, 389.

[19] J. A. Conkling, Chemistry of Pyrotechnics, Basic Principles and Theory, Marcel Dekker, Inc, New York, 1985

[20] [20a] W. Swift, A. Panek, G. Smith, G. Vogel, A. Jonke, Decomposition of Calcium Sulfate: A Review of the Literature, ANL-76-122, Argonne National Lab, 1976; [20b] A. Fuertes, M. Fernandez, The Effect of Metallic Salt Additives on Direct Sulfation of Calcium Carbonate and on Decomposition of Sulfated Samples, Thermochim. Acta, 1996, 276, 257; [20c] Z. Yan, Z. Wang, H. Liu, Y. Tu, W. Yang, H. Zeng, J. Qiu, Decomposition and Solid Reactions of Calcium Sulfate Doped with $\mathrm{SiO}_{2}, \mathrm{Fe}_{2} \mathrm{O}_{3}$ and $\mathrm{Al}_{2} \mathrm{O}_{3}$, J. Anal. Appl. Pyrol., 2015, 114, 389.

[21] D. Swanepoel, O. Del Fabbro, W. W. Focke, C. Conradie,Manganese as Fuel in Slow-Burning Pyrotechnic Time Delay Compositions, Propellants Explos. Pyrotech. 2010, 35, 105.

[22] A. Merzhanov, A. Averson, The Present State of the Thermal Ignition Theory: An Invited Review, Combust.Flame 1971, 16, 89. 